\title{
Animal Health and Welfare in Organic Agriculture
}

Senior Researcher Lois Philipps explores animal welfare issues in organic systems

At the end of March I had the opportunity to attend the 4th Network Animal Health Welfare in Organic Agriculture (NAHWOA) workshop at Wageningen in the Netherlands.

This workshop was concerned with the topic of breeding and feeding for health and welfare in organic farming systems. The meeting opened with a plea from Engelhard Boehncke from the University of Kassel to "put feeding and breeding above yield and productivity; there is an increasing need to put food quality to the forefront and get away from cheap mass produced food."

\section{Breeding for health and welfare}

Much of the breeding papers focused on dairy production, it was quite difficult to get information on beef and sheep breeding. Pigs and poultry had more information available.

The key points from the breeding discussions were:

- To define our breeding goals/objectives.

- To have a better understanding of how genotype and environment interact Organic farming needs to have a better understanding of what methods of selection and reproduction techniques it will accept in the future.

- How wide is the genetic base if organic farmers use the same top 10 breeding bulls as recommended in the conventional sector?

- How can we open up the debate with breeding companies and breed societies?

- Organic systems are well defined. We should be 'changing' the cows to fit the system not the other way round.

\section{Feeding for health and welfare}

There were two types of presentation covered under this part of the programme: those that focused upon feeding for production goals and those that were looking for ways and means of feeding to protect the animal from disease or parasitic infection. 
The key points from the feeding discussions were:

- The need for the development within certification to use 'feeding plans' much like the herd health plan although the herd health plan should already include feeding. Many of the key points require further research.

- For Pigs. Development of homegrown rations that included oil seeds and cereals.

- For Poultry. Better use of homegrown rations, clarification on the use of herbs, influence of different rations on the control of parasites, better understanding of the complementary nature of different parts of ration and its impact on the way the digestive tract works.

- For Beef. Silage quality, finishing rates, trace element requirements. In marginal areas feeding quality and the maintenance of bio-diverse swards. v For Dairy. Much of the debate was on when is forage a concentrate? Eg is Lucerne silage forage or a concentrate? Concerns over the variability in forage quality, how to manage regional trace element problems through feeding. There were still many questions over clover management in particular in marginal hill areas, and the more Mediterranean type climates.

Engelhard Boehncke produced a vision of the future after the discussions on the control of contagious and notifiable disease in Europe, but I believe that this vision/summary for the possible future of organic agriculture in Europe.

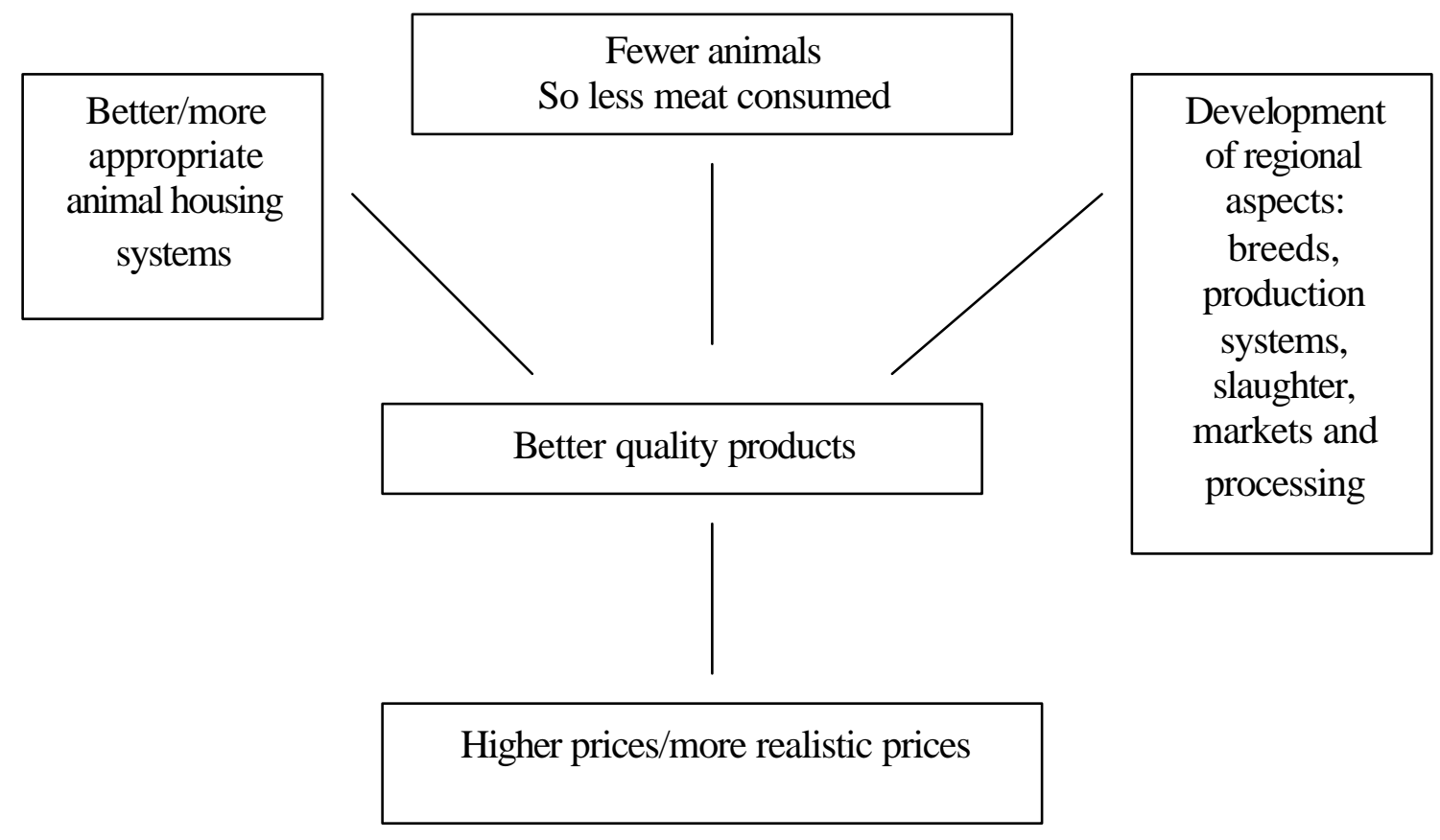


These are interesting issues and I am sure that many UK organic farmers which to contribute to the debate. For members of the OAS Beef and Sheep Group and OAS Dairy Groups there will be opportunities for discussion on breeding for organic farming systems in this year's programme.

For more information about the OAS farmer groups please contact the OAS office. 01488657600.

More information on the work and past meetings of NAHWOA can be found on the VEERU website which is at: www.veeru.reading.ac.uk/organic.

From: Elm Farm Research Bulletin No. 55, May 2001. 